\title{
O guia medicinal Primitive Physic[k] de John Wesley de 1747: ciência, charlatanismo ou medicina social? John Wesley's medical guide Primitive Physic[k] from 1747: science, charlatanism or social medicine?
}

Helmut Renders ${ }^{*}$

\begin{abstract}
Resumo
Em 1747, John Wesley, spiritus rector do movimento metodista, publicou a primeira edição do seu guia medicinal Primitive Physic $[k]$. Qual era o seu propósito num mundo onde a academia real, herbalistas, curandeiros/as, exorcistas e charlatães competiam pela atenção da população? O artigo apresenta os diferentes grupos que atuaram, ou pretendiam atuar, em prol da saúde na Inglaterra do século 18, e compara o conteúdo do guia Primitive Physic [k] com suas propostas e estratégias terapêuticas. Conclua-se que uma parte significativa do guia é composta por orientações da academia real de medicina, mas que sempre se favorecem remédios caseiros, com ingredientes acessíveis para as classes mais humildes. Quanto à chamada Spiritual Physick, menciona-se a oração como medida complementar, mas ignora-se plenamente a prática do exorcismo.
\end{abstract}

Palavras-chave: John Wesley; saúde; Guia medicinal popular; Primitive Physic[k]; academia real de medicina; herbalismo; curandeirismo.

\begin{abstract}
In 1747, John Wesley, spiritus rector of the Methodist movement, published the first edition of his medical guide Primitive Physic [k]. What was its purpose in a world where the Royal Academy, herbalists, healers, exorcists and quacks competed for the attention of the population? The article introduces the different groups who promoted or pretended to promote health in 18th century England and compares the contents of the guide Primitive Physic[k] with their proposals and therapeutic strategies. The conclusion is that a significant portion of the guide consists of guidelines of the Royal Academy of Medicine, but that it always favors homemade remedies with ingredients available to humbler classes. In relation to the so called Spiritual Physick, prayer is mentioned as a complementary measure, but the practice of exorcism is totally ignored.

Keywords: John Wesley; health; Popular Medicinal Guide; Primitive Physic[k]; Royal Academy of Medicine; herbalism; healers.

Artigo recebido em 27 de fevereiro de 2011 e aprovado em 10 de maio de 2011.

* Doutorado em Ciências da Religião (UMESP, BRA, 2006). Em março 2010 ingresso no Programa de PósGraduação em Ciência da Religião da Universidade Federal de Juiz de Fora como pós-doutorando. É professor associado da Universidade Metodista de São Paulo. País de origem: Brasil. E-mail: helmut.renders@metodista.br
\end{abstract}

Horizonte, Belo Horizonte, v. 9, n. 21, p. 339-353, abr.jun. 2011 - ISSN: 2175-5841 


\section{Introdução}

Doenças, suas causas e superações são uma das grandes preocupações da humanidade em busca de lidar com a sua finitude e mortalidade. No Brasil contemporâneo, encontramos lado a lado concepções e explicações bastante distintas das suas causas e propostas para as suas superações. Há a medicina moderna com base científica, a medicina alternativa, e o entendimento que doenças sejam causadas por espíritos ou demônios. $\mathrm{Na}$ igreja, existe uma competição entre cosmovisões pré-modernas, modernas e suas releituras pós-modernas em busca da explicação de doenças. Nesta competição, visita-se, às vezes, a tradição em busca de um argumento conclusivo em defesa de uma ou outra compreensão e o discurso relacionado.

Queremos contribuir para esta discussão e propomos investigar uma publicação pouco comentada - e ainda menos documentada - no Brasil, um guia de medicina popular chamado Primitive Physic $[k]^{2}$, de autoria do sacerdote anglicano e spiritus rector do movimento metodista, John Wesley (1703-1791).

\section{A promoção da saúde no século XVIII: agentes e propostas}

O guia Primitive Physic $[k]$ foi escrito nos meados do século 18. Numa época em que até um terço das crianças não alcançou o primeiro ano de vida e na qual epidemias eram a primeira causa de morte para o restante, o tema da saúde se impôs a qualquer agenda (HARRISON, 2004, p. 29) e, especialmente, a quem se preocupava com as populações mais pobres.

O século 18 foi uma época de transição. Saberes antigos foram, ao mesmo tempo, superados por ou mesclados com saberes novos. A área da religião e da saúde não fazia exceção dessa regra. Veatch (2004, p. 53-70) refere-se mesmo à época da "Integração da medicina e das humanidades" com o suposto fim dessa próximidade por volta de 1804 (2004, p. 71). Como data inicial dessa "integração", propõe Burstein (1955, p. 16) os anos 1525 e 1526, quando da publicação dos textos dos médicos gregos de Galen (200-130 a.C.) e Hipócrates (460-370 a.C.).

\footnotetext{
${ }^{2}$ Até 1760 sem “k”.
} 
Mas quais eram os grupos que cuidavam da saúde na época ou que queriam lucrar com ela?

\subsection{Curandeiras e curandeiros}

Um primeiro grupo representava os curandeiros e as curandeiras. Eles eram "leigos/as" no sentido de carecerem de qualquer tipo de formação universitária. As suas práticas baseavam-se em sabedoria popular em relação ao uso de plantas medicinais. Além disso, podemos imaginar um amplo leque de costumes religiosos regionais e cristãos que acompanhou o uso das plantas tanto na sua aplicação pelo povo quanto por leigos/as. Na Europa continental, esses conhecimentos populares, especialmente enquanto mulheres conhecedoras de métodos de planejamento familiar, caíram, em parte, sob a suspeita geral de magia e bruxaria. ${ }^{3}$

\subsection{Os herbalistas}

O segundo grupo eram os herbalistas. Eles levantaram sistematicamente o conhecimento sobre os efeitos medicinais de plantas. (cf. ARBER, 1986). Um dos mais antigos livros ingleses impressos do gênero data de 1578 e era uma tradução do francês (DODOENS, 1578). Estes herbários - livros com descrições de plantas, frutas, legumes e seus efeitos medicinais - eram expressões importantes da medicina renascentista em continuidade dos herbários medievais pintados, arte cultivada, especialmente nos monastérios.

\subsection{As academias reais de medicina}

A Escola Real de Medicina de 1518, a Escola Real dos Cirurgiões de 1540 e a Sociedade Real de Londres para o Progresso do Conhecimento da Natureza, fundada em

\footnotetext{
${ }^{3}$ Compare o alemão "Kräuterweib" (mulher [conhecedora] de ervas) e "Kräuterhexe" (bruxa das ervas). Neste imaginário a bruxaria é, essencialmente, relacionada com o conhecimento de ervas, e cada conhecedora dessa área está - potencialmente - sob a suspeita de ser uma bruxa. O respectivo imaginário brasileiro não é inglês, mas moldado pelo imaginário português e espanhol.
}

Horizonte, Belo Horizonte, v. 9, n. 21, p. 339-353, abr.jun. 2011 - ISSN: 2175-5841 
1660, colaboraram na proposta de tirar a medicina das mãos de charlatães e do campo da superstição. ${ }^{4}$ Nullius in verba, o lema da última sociedade, articulava a rejeição de uma ciência baseada em afirmações ou tradições não verificadas por métodos empíricos. Parte desse processo eram a definição da formação profissional dos médicos, a promoção da pesquisa empírica em revistas científicas e o cadastro dos profissionais da área. Somente no século 18 a medicina se emancipou da práxis da autorização episcopal para leigos/as atuando como médicos, por meio de um ato parlamentar (BURSTEIN, 1955, p. 18).

\subsection{Os exorcistas}

O exorcismo ${ }^{5}$ era, na perspectiva da Igreja oficial, restrito aos sacerdotes anglicanos. Para isso, cada diocese anglicana tinha um sacerdote designado a essa tarefa (para o âmbito católico, confira o exorcista católico Gassner [1727-1779]). Em consequência, a grande maioria dos sacerdotes não eram exorcistas. De fato, esse ministério estava, no século 18 , em pleno declínio.

Isso acompanha em termos gerais o tratamento da bruxaria pelo código penal. A bruxaria participava no mesmo imaginário do exorcismo, porque foi entendida como uma forma de manipulação ou invocação de poderes diabólicos. Sua punição por pena de morte foi estabelecida por Henrique VIII, em 1542, mas somente ratificada pela Rainha Elizabete em 1562 (cf. BURSTEIN, 1955, p. 23). Esses atos tiraram o chamado "benefício do clero": a liberação de acusação para pessoas que sabiam ler uma passagem da Bíblia ou tinham memorizado o salmo 51 (BAKER, 2002, p. 13-15) ${ }^{6}$. A partir de 1563, ficou também sob pena de morte a consulta de bruxos/as e, em 1604, foi incluída a invocação de "espíritos familiares". Somente em 1735, durante o governo de George III, a pena de morte foi transformada em pena de prisão ou envio para as colônias [de prisão].

A necessidade do exorcismo para o processo terapêutico foi ainda reafirmada em 1677 pelo pastor e médico puritano Webster (apud BURSTEIN, 1955, p. 32), que discursou na sua obra sobre a causa demoníaca de doenças ou fatalidades.

\footnotetext{
${ }^{4}$ Rogal (1978, p. 81) classifica a Escola Real dos Médicos como um clube elitista fechado da classe alta.

${ }^{5}$ Originalmente a palavra ex-ortar não significa livrar de um horkos (juramento) - ou ex-pulsar demônios -, mas fazer um juramento [a favor de Cristo]. Ele simboliza, então, um rito da aceitação do senhorio de Cristo sobre uma vida.

${ }^{6}$ Em outras áreas foi mantido e vinculado em 1706 com a deportação para as colônias como a Geórgia.
} 


\subsection{A tradição dos pastores médicos}

Tanto os pastores puritanos (VEATCH, 2004, p. 46) como os sacerdotes anglicanos (VEATCH, 2004, p. 53-55) tinham, nos séculos 17 e 18, muitas vezes, uma formação universitária em medicina. Em relação aos tratamentos e remédios, uma parte desses pastores e sacerdotes seguia a tradição da prevenção por meio de exercícios e $\operatorname{dietas}^{7}$ e da terapia por meio do uso de plantas medicinais, ou seja, da escola grega da medicina, que seguia a tradição dos chamados naturalistas. Não fizeram parte do seu propósito intervenções cirúrgicas e exorcismos ${ }^{8}$, mas certamente orações.

A proximidade entre teologia e medicina se expressa nas atribuições dos sacerdotes anglicanos que acompanhavam os seus paroquianos em todas as fases da sua vida. Entre outros, a visitação de doentes era uma parte integral do seu ministério. Joseph Townsend (1786, p. 17) considerou isso no fim do século XVIII uma tarefa impossível e, por essa causa, "desumana" para os sacerdotes:

Para um ser humano com sensibilidade comum nada pode ser mais angustiante do que escutar as queixas de infelicidade [ser desventurado / maldição] sem o poder responder adequadamente, e ser diariamente familiarizado com a miséria, sem poder de fugir dela e sem poder de trazer o alívio. Esta é a situação atual do clero, que, segundo a virtude do seu ofício, é obrigado a visitar as habitações dos pobres. Aqui eles veem uma infância indefesa, idosos decrépitos, a viúva e o órfão, alguns necessitando de alimento, outros de remédios, todos em tal número que nenhuma fortuna privada poderia fornecer o que eles precisam.

Para Townsend, a tarefa de cuidar dos pobres e doentes não tinha mais solução, especialmente pelos custos dos remédios "modernos" para restaurar a saúde, e dos alimentos para mantê-la. Seu olhar econômico combinado a uma ideia da necessidade de políticas públicas para não arruinar o Estado levaria a propostas autoritárias do trato da questão da saúde sem muita perspectiva para os pobres e marginalizados.

\footnotetext{
${ }^{7}$ Veja, por exemplo, Bunyon. No seu Peregrino, ele estabelece uma relação direta entre o paraíso e comida vegetariana. Uma posição típica renascentista com bases da medicina grega e conotações sociais: carnes eram caras e por causa disso consideradas para a grande massa da população, a qual Wesley se refere como bulk of mankind, comida nobre e inacessível.

${ }^{8}$ Era o caso também de John Wesley: "Busquei como assessores um boticário e um cirurgião experiente, para deixar todos os casos difíceis e complicados para os médicos segundo a escolha dos pacientes" (Cartas, II, 307)" (apud ROGAL, 1978, p. 84)
} 
Apesar da autolimitação dos pastores à área da prevenção, a Academia Real entendeu estes pastores mais como curandeiros, senão charlatães; certamente, não como médicos.

\subsection{Os charlatães}

Além dos grupos mencionados, houve mais uma categoria atuando na área da saúde que não se encaixa nos modelos até agora apresentados. Trata-se de vendedores ambulantes de remédios à base, por exemplo, de mercúrio - quicksilver em inglês, por certo tempo considerado de efeito milagroso. Desse uso vem a sua designação como quacks, sinônimo de charlatães (Cf. Também SCLIAR, 2005, p. 38). A luta contra eles demorou até o século 20 (CRAMP, 1911) ${ }^{9}$ e além. Este grupo apresentou as suas misturas criadas sem pesquisa empírica nenhuma, baseadas num ideário alquimista ou simplesmente atendendo a superstições quanto ao efeito medicinal de uma rica variedade de substâncias.

\section{Considerações intermediárias}

Tanto o clero como os/as leigos/as relacionaram em graus diferentes, chamando na época spiritual physick - medicina espiritual que abrangia tudo entre oração, mediação do perdão (LUND, 2006, p. 667) e exorcismo (DAVIES, 1997, p. 261) ${ }^{10}$ - e physick - a medicina, contando tanto com as áreas da prevenção como da terapia à mera base de experiência e observação. Como a Igreja Católico-Romana, dioceses anglicanas mantiveram, na época, um sacerdote nomeado como "exorcista oficial”, às vezes para contornar propostas populares de spiritual physick, às vezes por convicções muito similares.

As estratégias distintas da spiritual physick e da physick não se distribuíram tão claramente entre leigos e sacerdotes do clero. Os/As curandeiros/as, por exemplo, consideramos leigos/as por causa da falta de uma formação universitária, mas certamente incluíam práticas religiosas e exercitavam, dessa forma, um tipo de sacerdócio universal. Já alguns pastores eram mais exorcistas (talvez um pouco mais a tendência puritana), outros

\footnotetext{
${ }^{9}$ Schritzmeyer (1997, p. 135-145) investigou o charlatanismo como assunto em tribunais brasileiros. Chama a atenção a sua identificação com o curandeirismo.

${ }^{10} \mathrm{O}$ autor descreve o exorcismo como crença popular. Como a Igreja Católico-Romana, dioceses anglicanas têm até hoje um sacerdote nomeado como "exorcista oficial".
} 
mais empiristas (segundo a nossa impressão, em grande parte a tendência anglicana e certamente dos deístas e latitudinaristas entre eles). Isso pode representar também a proximidade ou distanciamento dessas igrejas em relação ao povo comum.

No século 18, a medicina universitária se tornou mais cara e mais inacessível para as classes populares. Isso favoreceu, até refortaleceu, a prevalência da procura de práticas não científicas no âmbito das classes populares. É esta lacuna que alguns guias "populares" de medicina pretendiam preencher. Entre eles, o guia de John Wesley.

\section{Primitive Physic[k] - um guia medicinal popular do ano 1747}

Homo sum; humani nihil a me alienum puto ${ }^{11}$. Wesley 1747

Primitive Physic[k], publicado pela primeira vez em $1747^{12}$, era um guia medicinal direcionado às populações pobres sem acesso à medicina que até hoje aparece em publicações inclusive em língua portuguesa. ${ }^{13}$

\subsection{Wesley e os herbalistas}

Quanto aos herbalistas, chama a nossa atenção, primeiro, o próprio nome Primitive $\underline{P h y s i c / k l}$. Ele recorre à, na época ainda popular, designação de médicos como físicos, o que significa "naturalistas". ${ }^{14} \mathrm{O}$ guia segue um método baseado na observação de doenças e

\footnotetext{
${ }^{11}$ Subtítulo na capa; Tradução: "Sou ser humano; nada do que é do ser humano é estranho para mim". A expressão é do dramaturgo Publius Terentius Afer (195/185-159 a.C.), escritor de comédias prestegiado na época da Renacença. Este aspecto combina bem com o carater de medicina apresentada no livro, mas, certamente não seria uma escolha de um puritana inglês.

${ }^{12}$ Segundo Rogal (1978, p. 82), entre 1660 e 1785 foram publicados por outros autores nada menos do que 12 diferentes guias de medicina para as classes populares: "Assim, não representou choque para ninguém quando [...] John Wesley [...] publicou a sua contribuição para a saúde geral e bem-estar da nação."

${ }^{13} \mathrm{O}$ guia é até hoje citado com referências ao vegetarianismo (FERREIRA, [2007]), e à epidomologia ou higiene (BEAL-PRESTON, [2007]). No mundo anglo-saxão ele é discutido por médicos, farmacêuticos/as, psicólogos/as e teólogos/as (CALLAWAY, 1974, p. 318-324; ROGAL, 1978, p. 81-90; BARDELL, 1979, p. 111-121; BOLANDER, 1983, p. 3-10; TRANTER, 1989, p. 92-93; MALONY, 1996, p. 147-159; MADDEN, 2004, p. 365-378 e 2007, p. 11-298).

${ }_{14}$ Futuramente gostaríamos de comparar este imaginário com o imaginário colonial brasileiro. Segundo Rodrigues (2001, p. 136), "Os físicos, como então eram chamados os médicos, estavam entre os primeiros exploradores do novo mundo. Tinham como objetivo pesquisar a flora e a fauna da nova terra, que classificaram de acordo com o sistema que conheciam e compreendiam. A farmacopeia indígena teve seus elementos estudados e classificados de acordo com os princípios hipocráticos".
}

Horizonte, Belo Horizonte, v. 9, n. 21, p. 339-353, abr.jun. 2011 - ISSN: 2175-5841 
do efeito terapêutico de exercícios físicos e plantas medicinais. Wesley (1764, p. HK e HO) descreve herbalistas simplesmente como conhecedores de plantas. No guia, expressa seu respeito pela respectiva sabedoria de povos indígenas, de romanos e gregos, por serem conhecedores de plantas medicinais, acumulando conhecimentos milenares. A prática de medicina familiar ou tribal desses povos, passando os conhecimentos do pai para o filho ou do sacerdote-curandeiro para o próximo, servia como inspiração para o uso de Primitive Physic[k].

\subsection{Wesley e a Physick da Academia Real da Medicina}

Na universidade de Oxford, Wesley tinha estudado medicina (VEATCH, 2004, p. 47-53) sem se formar na área.

Maddox (2007, p. 5) registra a leitura de no mínimo sete obras maiores de médicos consagrados feitas por Wesley entre 1724 e 1732, e Rogal (1978, p. 84) menciona a leitura de mais 14 obras publicadas entre 1743 e $1785 .{ }^{15}$ Isso dá um total de, no "mínimo", 21 obras, ou seja, Wesley se dedicou à leitura contínua da produção científica na área da medicina da sua época. No Primitive Physic[k], Rogal (1978, p. 87) identificou vinte citações de “...obras de médicos britânicos ou do continente europeu”, e Donat (2006) concluiu que cerca de um terço do conteúdo do livrinho se baseasse em autoridades medicinais da época.

Mas, apesar dessa evidente estatística, houve dúvidas. Madden lembra o conflito de John Wesley com o médico anglicano Dr. William Hawes, e Rogal (1978, p. 84) passa-nos a reação irônico-provocativa do próprio Wesley quanto às críticas recebidas:

\footnotetext{
Meu livreiro me informa que, desde que você publicou suas observações sobre o Primitive Physick, teria havido uma demanda maior para ele do que nunca. Se, portanto, você, por favor, pudesse publicar algumas observações mais, você me conferiria mais um favor. Seu humilde servo, John Wesley, Londres, 20 jul. 1776
}

Schofield (1953, p. 340) resumiu de forma mais genérica: "Ele não sabia muito das ciências [...], mas ele não tinha desgosto das ciências nem ignorava as ciências".

\footnotetext{
${ }^{15}$ Segundo Maddox (2007, p. 5), John Wesley leu entre 1724 e 1732 no mínimo sete obras maiores de médicos consagrados da sua época. Rogal (1978, p. 84) menciona a leitura de mais 14 obras publicadas entre 1743 e 1785.
} 
É nossa impressão que Wesley não se aprofundou em todos os detalhes, mas que jamais teria rejeitado a ciência por razões principais. Isso já fica visível pela ampla integração de receitas de autores vinculados com a Academia Real. Além disso, lembra Hass (1994 p. 386 e 391) que a mera noção do limite do conhecimento medicinal científico, assunto levantado por Wesley eventualmente numa ou noutra ocasião, de fato estaria em pauta até na atual discussão sobre as ciências. Assim, o ceticismo de Wesley quanto à idealização cega das ciências parece até bastante moderno.

\subsection{Wesley e Spiritual Physick}

Concordamos com Madden (2007, p. 36) que “... como sacerdote, Wesley considerava permissível a se mover entre os mundos da providência e do físico. A sua aproximação à medicina em Primitive Physick era cuidadosamente empírica, enquanto seu entendimento da cura era integral". Integral quer dizer aqui que Wesley considerava o aspecto religioso nos processos terapêuticos e nas práticas curativas.

Essa visão integrada fica evidente na forma como Wesley se refere no seu guia a uma das expressões da Spiritual Physic[k], a oração: “... adicione ao tudo, pois não é trabalho perdido, a antiga medicina da oração e de ter fé em Deus" (apud ROGAL, 1978, p. 89). Chama a atenção o verbo "adicionar". A oração é para Wesley uma práxis comum e, certamente, a sua ênfase empírica quanto ao tratamento e à prevenção medicinal não quer substituir o papel do criador no processo terapêutico. Vimos este aspecto já na sua valorização de ervas justamente por serem consideradas frutos da boa criação de Deus. Porém, chama a atenção que Wesley, no seu guia, não adiciona o remédio à oração, mas, a oração ao remédio... Parece que Wesley é aqui até mais médico-pastor do que pastormédico... Diante desse resultado, surpreende que esta simples inclusão da oração no processo terapêutico basta para que Hay e Rogers (1997, p. 169-170) julguem Wesley como supersticioso. Isso nos parece inadequado, especialmente porque não se trata da rejeição ou substituição de um tratamento medicinal pela oração, mas da religação do tratamento medicinal com a graça divina. 


\subsection{Wesley um "quack"?}

Em casos raros Wesley foi considerado um quack (KING, 1957), apesar das frequentes críticas do próprio Wesley em relação à atuação dos quacks e de seu aproveitamento da fragilidade das pessoas doentes. Foi justamente em resposta a este abuso da necessidade do povo que o guia Primitive Physic [k] foi escrito. Mesmo que um ou outro remédio sugerido pelo livro fosse um produto parecido com aqueles comercializados pelos quacks, podemos dizer que Primitive Physic[k] custou pouco e já por causa disso não deria dado lucro.

\subsection{Wesley e o exorcismo}

Sendo o guia, fundamentalmente expressão do "empirismo" grego, a outra leitura de doenças na Antiguidade, que partia da compreensão de demons, espíritos maus como causa de doenças, não se encontra no livro Primitive Physic $[k] .{ }^{16} \mathrm{O}$ fato em si, entretanto, não seria um argumento plenamente conclusivo. Primeiro, como sacerdote anglicano, Wesley certamente não favorecia exorcismo popular ou, no caso, até familiar. Assim, poderíamos argumentar que também não se esperaria no guia, digamos, uma seção sobre exorcismo, sendo ele um manual para o laicato. Mas, justamente, um guia para o laicato poderia ter contido um conselho tipo: "caso apareçam problemas de tal caráter, procure um sacerdote para fazer um exorcismo". A ausência deste tipo de orientação pesa e leva-nos à conclusão que Wesley não integrou o exorcismo na práxis terapêutica comum. Como exemplo, serve a discussão da época sobre o caráter da chamada "melancolia". A doença "divina" de Hipócrates era, na época de Wesley, ainda por muitos considerada efeito de poderes malignos, hoje em dia não muito longe da relação estabelecida entre depressão e demônios, por exemplo, pela Igreja Universal do Reino de Deus. Wesley rompeu com essa compreensão e seguia Robert Burton e sua ênfase nas causas físicas ou naturais dessa doença (Cf. LUND, 2006, p. 665-683).

\footnotetext{
${ }^{16}$ Usando a distinção de Foster (apud RODRIGUES, 2001, p. 132-133): Wesley não seguia um sistema "personalístico", mas, "naturalístico" em qual “... o indivíduo não é vítima, mas agente de sua própria doença".
} 
Finalizamos considerando que cura e exorcismo não andavam "naturalmente" de mãos dadas em Wesley, em que o exorcismo jamais foi visto como uma parte indispensável da sua proposta da recuperação, manutenção ou promoção de saúde.

Precisamos, entretanto, sinalizar que, fora do livro Primitive Physic $[k]$, o quadro é mais complexo. Wesley considerava a existência de fantasmas (ghosts) e espíritos, chamados por ele "anjos maus". Na sua introdução de Panorama da sabedoria de Deus na criação ele afirma:

\begin{abstract}
O que sobra para a filosofia natural é a doutrina sobre Deus e os espíritos. Em relação a isto, não podemos depender da razão ou do experimento. Isso deve ser deduzido dos oráculos de Deus. Em relação a isto, então, não procuramos novos avanços, mas permanecemos nas boas e antigas trilhas: a nos contentar com aquilo que Deus aceitou revelar (WESLEY, 1763, p. 28).
\end{abstract}

Alguns autores falam, por causa disso, que o metodismo teria promovido até o retorno das crenças populares, especialmente nas populações rurais. Acreditamos que fosse mais adequado dizer: o metodismo nascente nem dependia nem ajudou preservar esta cultura antiga, mas a sua abertura ao pensamento popular religioso ajudou na aceitação do metodismo pelas classes mais populares (DAVIES, 1997, p. 265).

Aceitando o imaginário, Wesley considerava a manipulação da vida pelo apelo ao diabólico uma possibilidade real. Assim, ponderava a bruxaria ou feitiçaria como perigo vital. ${ }^{17}$ A razão por manter o respectivo imaginário se basearia, em última instância, em sua compreensão do texto bíblico, não na sua pesquisa empírica. Seguia a regra simples que tudo que consta na Bíblia devesse prevalecer como existente e relevante para a cosmovisão. Poderíamos dizer: quando Wesley ignora seu próprio método religioso da interpretação do texto bíblico, ele abre o leque para conceituações demonológicas de doenças. ${ }^{18}$ Assim também Schofield (1953, p. 338), apesar de minimizar o peso disso no cotidiano da medicina social e popular promovido por Wesley. Concordamos com o autor e afirmamos que, na proposta terapêutica de guia, não há indícios para uma práxis de exorcismo. Jamais

\footnotetext{
${ }^{17}$ Sua posição é parecida a de William Drage (1665, apud BURSTEIN, 1955, p. 21), que não argumenta empiricamente, como testemunho ocular, mas biblicamente. Este argumento era para a Academia Real de Medicina símbolo de uma atitude não empírica e, por causa disso, no mínimo, potencialmente supersticiosa.

${ }^{18}$ A respectiva afirmação pontual na literatura metodista brasileira é, então, eventualmente correta, entretanto, quanto ao livro Primitiv Physic[k] absolutamente incorreta.
}

Horizonte, Belo Horizonte, v. 9, n. 21, p. 339-353, abr.jun. 2011 - ISSN: 2175-5841 
foi considerado algo comum ou naturalmente integrado no processo do restabelecimento da saúde.

\section{Considerações finais}

Quanto à pergunta inicial, respondemos que o guia medicinal Primitive Physic[k] é um texto escrito para a promoção da medicina familiar, capacitando pessoas simples a seguir dietas, produzir "remédios" e aplicá-los. Resta a memória que no mínimo um terço desses remédios foi cuidadosamente coletada de livros medicinais da época, e que um critério da sua inclusão no guia era a sua produção à base de plantas locais, de acesso fácil. Wesley afirma ter testado todos, ou seja, além da sua origem supostamente "confiável", ele verificou a sua eficácia pessoalmente. E mesmo que essa afirmação fosse talvez um pouco exagerada, ela revela uma atitude "empírica" para garantir a manutenção e o restabelecimento da saúde popular. Com seu foco nas camadas mais humildes, sem acesso a tratamentos medicinais ou remédios mais sofisticados, a acusação de charlatanismo - do aproveitamento de miséria para lucrar - não encontra base: Primitive Physic[k] promoveu uma medicina preventiva e gratuita, é capacitação, não aproveitamento.

O guia une a ciência da época a uma espiritualidade à base da oração como atitude de gratidão e expressão da dependência de Deus. Dificilmente isso caracterizaria uma atitude "supersticiosa". Outras formas populares da Spiritual Physic [k], como o exorcismo, não são integradas no guia nem mencionadas como plano "b" em casos excepcionais.

\section{Referências}

ARBER, Agnes. Herbals, their origin and evolution: a chapter in the history of botany 1470-1670. Cambridge: Cambridge University Press, 1986.

BAKER, John Hamilton. An Introduction to English legal history. 4. ed. Cambridge, Inglaterra: Cambridge Paperback Library, 2002.

BARDELL, E. B. Primitive Physick: John Wesley's receipts. Pharmacy in History, v. 21, n. 3, p. 111-121, 1979. 
BERTUCCI, Paola. John Wesley and the religious utility of electrical healing. British Journal for the History of Science: British Society for History of Science, v. 39, p. 341362, set. 2006.

BITTENCOURT FILHO, José. Matriz religiosa brasileira: religiosidade e mudança social. Petrópolis: Vozes, 2003.

BOLANDER, V. A preliminary examination of John Wesley's 'Primitive physick'. The Bookman, v. 10, n. 4, p. 3-10, jul./ago. 1983.

BROWN, P. S. Herbalists and medical botanists in mid-nineteenth-century Britain with special reference to Bristol. Medical History, v. 26, n. 4, p. 405-420, out. 1982.

BURSTEIN, Sona Rosa. Demonology and medicine in the Sixteenth and Seventeenth Centuries. Folklore, v. 67, n. 1, p. 16-33, mar. 1956.

CALlAWAY, C. W. John Wesley's Primitive Physick: an essay in appreciation. Mayo Clinic proceedings, v. 49, n. 5, p. 318-324, maio 1974.

DAVIES, Owen. Methodism, the clergy, and the popular believe in witchcraft and magic. The Historical Association, p. 252-265, 1997.

FERREIRA, Silvia. Vegetarianismo ao longo da história. CentroVegetariano. Disponível em: < http://www.centrovegetariano.org/Article-300-

Vegetarianismo+ao+longo+da+Hist\%25F3ria.html >. Acesso em: 22 nov. 2007.

DEMLING, Joachim Heinrich e THIERAUF, Paul. Zur ärztlichen Einschätzung von 'dämonischer Besessenheit': Ein nicht nur historischer Abriss. Wege zum Menschen, v. 62, n. 4, p. 332-349, 2010.

DODOENS, Rembert. A nievve herbal, or, Historie of plantes [...]. London, 1578. Disponível em: 〈http://www.botanicus.org/bibliography/b12075577>. Acesso em: 12 jul. 2010.

DONAT, James G. The Rev. John Wesley's Extractions from Dr Tissot: A Methodist Imprimatur. Science History Publications, v. 39, p. 285-298, 2001.

DONAT, James G. Empirical Medicine in the 18th Century: The Rev. John Wesley's Search for Remedies that Work. Methodist History, v. 44, n. 4, p. 216-226, 2006.

HARRISON, Mark. Disease and the modern world: 1500 to the present day. Cambridge: Polity, 2004.

HASS, Jr. J. W. John Wesley's views on science and Christianity: an examination of the charge of antiscience. Church History, v. 63, p. 378-392, 1994. 
HAY, Douglas; ROGERS, Nicholas. Eighteenth-Century English Society: Shuttles and swords. Oxford: Oxford University Press, 1997.

HEMPTON, David. Methodism: Empire of the Spirit. New Haven: Yale University Press, 2005.

HILL, Alfred Wesley. John Wesley among the physicians: a study of eighteenth-century medicine. London: Epworth, 1958. [Série: The Wesley Historical Lecture, 24].

HOGHES, David R. Spiritual ecopmaps: a new diagrammic tool for assessing marital and family spirituality. Journal for marital and family therapy, v. 26, n. 2, p. 217-228, 2000.

HUGHES, M. D. The holistic way: John Wesley's practical piety as a resource for integrated healthcare. Journal of Religion and Health, v. 47, n. 2, p. 237-252, set. 2007.

KING, LESTER S. The Medical World of the I8th Century. Chicago: The University of Chicago Press, 1958.

LUND, Mary Ann. Robert Burton the spiritual physician: religion and medicine in the anatomy of melancholy. The Review of English Studies, New Series, v. 57, n. 232, p. 665683, 2006.

MADDEN, Deborah. Contemporary reaction to John Wesley's Primitive Physic: or, the case of Dr. William Hawes examined. Social History of Medicine, v. 17, n. 3, p. 365-378, 2004.

MADDEN, Deborah. 'A cheap, safe and natural medicine': Religion, medicine and culture in John Wesley's Primitive Physic. Clio Medica, v. 83, p. 11-298, 2007.

MADDEN, Deborah. A Cheap, Safe and Natural Medicine: Religion, Medicine and Culture in John Wesley's Primitive Physic. Amsterdam: Rodopi, 2007.

MADDOX, Randy L. John Wesley on holistic health and healing. Methodist History, ano 46, n.1, p. 4-33, out. 2007.

MALONY, J. John Wesley's Primitive Physick: An 18th-century Health Psychology. In: Health Psychology, v. 1, p. 147-159, 1996.

RODRIGUES, A. Greco. Buscando raízes. Horizontes Antropológicos, Porto Alegre, v. 7, n. 16, p. 131-144, dez. 2001.

ROGAL, Samuel. Pills for the poor: John Wesley's Primitive Physick. The Yale Journal of Biology and Medicine, v. 51, p. 81-90, 1978.

SCHOFIELD, Robert E. John Wesley and Science in the 18th century. Isis, v. 44, p. 331340, dez. 1953. 
SCLIAR, Moacyr. Do mágico ao social: trajetória da saúde pública. 2. ed. São Paulo: Senac, 2005.

TRANTER, J. John Wesley's primitive physic. An easy and natural method of curing most diseases. International Journal of Dermatology, v. 28, n. 2, p. 92-93, mar. 1989.

VEATCH, Robert M. Disrupted dialogue: medical ethics and the collapse of physicianhumanist. Oxford: Oxford University Press, 2004.

WESLEY, John. Primitive physick: or, an easy and natural method of curing most diseases, London: printed and sold by Thomas Trye near Gray's-Inn Gate, Holborn, 1747.

WESLEY, John. A survey of the wisdom of God in the creation: or a compendium of natural philosophy: v. 2. Bristol: William Pine, 1770.

WESLEY, John. The complete English Dictionary: explaining most of those hard words, which are found in the best English writers. By a lover of good English and common sense. N.B. Bristol: Printed by William Pine, 1764.

WEBSTER, John. Displaying of supposed Witchcraft. London: Printed by J. M., 1677. 